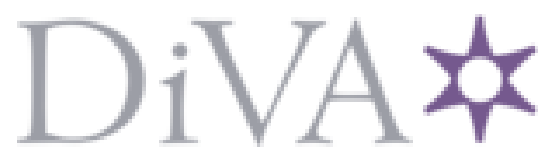

http://www.diva-portal.org

This is the published version of a paper published in Janus Head.

Citation for the original published paper (version of record):

Kalman, H. (2013)

Faking orgasms and the idea of successful sexuality.

Janus Head, 13(1): 97-118

Access to the published version may require subscription.

N.B. When citing this work, cite the original published paper.

Permanent link to this version:

http://urn.kb.se/resolve?urn=urn:nbn:se:umu:diva-55650 


\title{
Faking Orgasms and the Idea of Successful Sexuality
}

\author{
Hildur Kalman \\ Umeå University, Sweden
}

In the Nordic countries, at a time when women have only recently won the right to their own bodies and to a sexuality of their own and for themselves, women nevertheless fake orgasms. Moreover, a common question posed to the Swedish Association for Sexuality Education (RFSU) deals with lack of desire. Not only are women faking and complaining of lack of desire, but men as well. It seems that contemporary ideals surrounding sexuality converge with quests for not only pleasure and love, but also for fitting in and experiencing what is conceived of as normal and "successful" sexuality. This essay examines the contemporary and prevalent phenomenon of faked orgasms from the perspectives of feminist theory and phenomenology.

\section{Introduction}

In 2007, while planning for a feminist anthology on the subject of faked orgasms, Susanna Alakoski and Amanda Mogensen invited Swedish women, by way of newspaper advertisement, e-mail postings, etc., to write anonymously about their orgasms, faked or real. The e-mail postings also reached women in other Scandinavian countries and Finland. They received an abundance of answers from the Nordic countries, a selection of which was published. Some of the contributors chose not to be anonymous, having made their own analysis and interpretation of their experiences. Two rather unexpected things turned up. The first was that the very first letter to arrive was from a man, and eventually they received more examples of male experiences of faking. The second surprising thing was there were also letters from lesbian women asking why the editors were not interested in their experiences of faking as well. At first the editors were hesitant to include such stories as their plan had been to give a picture of, and investigate, the heterosexual norm for sexuality from women's point of view. But eventually they decided to include the broader empirical material, which gave an even more complex and compelling picture of the norms for sexuality today. Further, they decided to invite experts and academics such as social workers, historians, counsellors, and myself as a philosopher - to write on the book's theme. ${ }^{1}$ In the book Fejkad Orgasm (Alakoski \& Mogensen, 2008-hereafter referred to as FO), the participating women and men provide many examples of experiences of faking along with their analyses and musings on the reasons for and circumstances surrounding faking. The contributors telling of their faked orgasms describe how they might move about, groan and moan a little extra, as well as say something about how good it was. Others tell of another kind of faking - where pleasure and enjoyment are overstated in direct or indirect terms. In 2007, RFSU (the Swedish Association for Sexuality Education) together with the 
TV programme Lustgården carried out a survey among 1000 women aged 18-35, and circa $25 \%$ of these women had at some point faked an orgasm. The most common explanation given for faking in this survey was that it was a way to put an end to the sex (FO, p. 88). Moreover, a common question posed to RFSU (the Swedish Association for Sexuality Education) deals with lack of desire. Not only are women faking and complaining of lack of desire, but men as well. This empirical background forms a point of departure for the present essay, the aim of which is to explore reasons for faking, and the values attached to orgasm that make it important enough to be faked, through the lenses of feminist theory and phenomenological reflection. $^{2}$

\section{The Orgasm-Both Important and Not Important}

For faking to be an option, there must first of all be an idea of orgasm-based either on earlier or vicarious experience. Secondly, to be worth faking, the orgasm must be assigned some importance or value. Thirdly, the orgasm must be conceived of as being possible to mediate through pretence, that is, as faked. Not even knowing it was possible to fake an orgasm, one woman writes about her first sexual intercourse: "Had I thought that a faked orgasm was expected of me, I would have cried out for the King and motherland. Thank God for ignorance!” (FO, 2008 p. $37) .^{3}$

In FO many different circumstances and reasons for faking are given-but two major kinds of faking surface: faking in the name of love and faking to put an end to the sex.

It would seem that the person who fakes orgasm out of love wants to meet and accepts his/her partner's expectation and hope of achieving the consummate erotic encounter-the completion of which is orgasm. Obviously, in these circumstances, the faker does not consider the orgasm to be particularly important — with regard to him-/herself. Seemingly, what is important at this point is to comply with the expectations of the other person-rather than to meet him/her in open-ended erotic play. It may be that the faker enjoys the moment tremendously, but is slightly disturbed by the expectations of an orgasm. But the question is, regardless of whether the faker wishes to comply with expectations or simply does not care about having an orgasm, and instead fakes one out of pure kindness, or to put an end to the sex, why is the orgasm important enough to be faked? 


\section{Orgasm as a Sign of Success}

Asking why the orgasm is important may seem somewhat ridiculous. But besides being very pleasurable, the orgasm is sometimes important enough to be faked. This brings us to the role orgasm has as a sign, the meaning of which is manifest in the interpretations that it generates. The orgasm functions as a sign in that it is interpreted and presented as an essential achievement, even when it is faked, and not having one is interpreted and presented as a failure. Note that, in this case, what shows on the surface, the form, seems to be more important than content-the extent to which one enjoys the sexual activity. From the experiences shared in $F O$ we learn that what seems to be at stake in many sexual encounters is the ability to "give" the other person an orgasm, where a woman's orgasm is the mark of success for a male partner. Thus one might claim that the person who is being exposed to the technicalities of sex has come to play a minor role in this situation, and the leading part in the orgasm performance is not the "I" who experiences the orgasm but the person who "gives" it. As one 25-yearold male writes, "The times when my buddies and I have talked about faked orgasms, it's been about our own. It's as if it's a greater defeat when the girl you're having sex with fakes it than when you do it yourself” (FO, p. 198).

To regard one's own needs as subordinate and to set one's own needs aside may, however, sometimes result in sexual practices best described as "ambivalent", as in the case of young women engaging in vaginal intercourse despite associated pain in order to prioritize their partner's enjoyment (Elmerstig, 2009). In an interview study with young Swedish women (14-20 years) who suffered variable degrees of coital pain during sexual intercourse, the women had sexual intercourse for their partner' sake, and considered their own experiences of pain insignificant compared with the sexual pleasure the partner gets. By feigning pleasure the women in the study strove to be affirmed in their image of an ideal woman, what "a sexually normal woman should be like". This ideal woman and perfect girlfriend was one who would be "willing to have sexual intercourse, ... perceptive of their partner's sexual needs, and . . . able to satisfy them". In fact, these women experienced themselves as "women" if they had sexual intercourse, otherwise not (Elmerstig, Wijma and Berterö 2008, p. 360-1). As one of them said: " ... well, I wanted it to be perfect, you know ... that it should be like in the love movies, when they have sex with each other and 
like 'oh, God it feels good,' sort of ... “ (p. 361). These examples, together with several of the contributions in $F O$, point to existing ideals concerning what is conceived of as a successful sexuality for both women and men, an important part of which is successfully providing pleasure and/or "giving" an orgasm to one's partner.

\section{The Body as a Situation-Our Grasp Upon the World}

Just as sexual experiences have their basis in individual biological bodies, our sexualities are formed in cultural and historical contexts. Phenomenology highlights the way in which the lived body encompasses and expresses its history and lived experience as well as its presently lived relation to the world. To cite Merleau-Ponty:

It is no more natural, and no less conventional, to shout in anger or to kiss in love than to call a table 'a table'. Feelings and passional conduct are invented like words. Even those which, like paternity, seem to be part and parcel of the human make-up are in reality institutions. It is impossible to superimpose on man a lower layer of behaviour which one chooses to call 'natural', followed by a manufactured cultural or spiritual world. Everything is both manufactured and natural in man, as it were, in the sense that there is not a word, not a form of behaviour which does not owe something to purely biological being-and which at the same time does not elude the simplicity of animal life, and cause forms of vital behaviour to deviate from their preordained direction, through a sort of leakage and through a genius for ambiguity which might serve to define man. (1962 [1945], p.189)

The lived body is a lived relation to the world, in that we have access to the world through our bodies. In the words of Simone de Beauvoir: the living body is "a situation", and "our grasp upon the world and the outline for our projects" (2010 [1949], p.46). Our experiences are given to us through the lived body, and lived relation to the world (of which we ourselves are a part). As embodied subjects, we are in a constant emotionally coloured interplay with our environment, and affectivity is a distinctive form of consciousness when we are relating to the world. Places, 
situations, people and things are experienced as speaking to, calling on, enticing or making appeals to us. In erotic encounters, this means that our own body as well as the other person's may appear to be happy, beautiful and wonderful (Merleau-Ponty 1962 , pp. 63, Heinämaa, 2003, pp. 67).

Moreover, the lived body has its own conditions_-both possibilities and limitations. In a tangible and embodied sense, every human being carries with her her own time, culture, and society, even when she engages in a sexual encounter. Some of the cultural expressions of embodiment and bodily appearances, such as a hairstyle or the bell-bottoms of last year, can be more easily changed than others. But the expressions given through the ways in which we "live" our bodies are not as easily changed. Because they are two sides of the same coin, experience and the expression thereof cannot be detached, nor can body and person be separated. In other words, the social and cultural ways in which we live our bodies-our gender and sexuality, our ways of perceiving ourselves, our having confidence in ourselves, and activities such as walking, running, throwing a ball, or making love-are all embodied (Young, 2005). We live in and are part of a symbolic universe where certain notions and ideas about the body and sexuality form part of how we perceive ourselves, our bodies and their needs, and our sexual lives.

\section{The Social Constitution of Bodies}

We have all been told, in different ways, what an orgasm should be like, and we even know what a faked orgasm should be like. Common references within popular culture are the imitation of a faked female orgasm in the film "When Harry met Sally" and episodes in the TV series "Seinfeld" and "Sex and the City" dealing with faked orgasm. Although these examples are taken from American popular culture, the circulation and impact of American popular culture in Sweden, for example, can hardly be overestimated. ${ }^{4}$

The body is socially constituted in two ways. First, the values and ideals of society are inscribed in bodies, through the ways in which we talk about the body and sexuality, and through the ways these are represented in the media, films, myths, and in counselling. From romantic portrayals to pornographic stagings, from the Song of Songs to the smashing spreads of weekly magazines with exciting advice, we are supplied with a set of repertoires to achieve the satisfactory sex life.

Second, the body is constituted through lived life. As social conditions and cultural values are lived and managed by us, they become sedimented 
or laid down within us, so to speak, becoming part and parcel of our experiences (cf. Merleau-Ponty 1962 [1945], p.130). In this way, social conditions are incorporated and can be seen in embodied habits-habits such as kissing, caressing, and even the ways in which orgasms are faked.

\section{The Conditioning of Sexual Experience}

In his analysis of perception, Merleau-Ponty distinguishes between the personal and the anonymous body. These are not two different entities, but he uses this distinction to focus on different aspects of experience. $\mathrm{He}$ suggests that our habits, our personal style, our personal way of seeing and experiencing, are formed like a fold in fabric (cf. Merleau-Ponty 1962 [1945], p. 215), or like "a wave on the sea surface" (Heinämaa, 2003, p. $51 \mathrm{n} .35)$. The surface on which the wave occurs, or the fold is formed, is the anonymous body, which is the basis of our ability to see, hear, etc. The personal body inherits this ability, as it were, where lived experience shapes our perception. The anonymous body both limits and enables new experiences and may elude our deliberate attempts at control, such as when an orgasm does not come as easily as one might wish, or it may surprise us, such as when we get goose bumps from listening to a piece of music or feel our hackles literally rise in fear. Engaging ourselves in a field of interest may tune and refine our attention in that area, whereas it may continue to be rather numb, or be numbed, in others (cf. Merleau-Ponty 1962 [1945], pp. $212 \mathrm{ff} ., 240)$. In this way, lived experience is partly constitutive of future experiences. Certain cultural "scripts" may be thus embodied, too, such as the notions we have of love and the way we "do" love. Such "scripts" are on the fringe of our encounters in love and sex, as part of what socially conditions our experiences of these encounters.

\section{A Sign of Love-Take One}

The person faking in the name of love for some reason lacks sufficient desire or arousal to be able to experience the joy of shared pleasure in an orgasm, but still wishes to make his/her partner feel like an accomplished lover, and like someone who is loved and loving. "I faked on my wedding night. I didn't want to make the bridegroom sad" one woman writes ( $F O$, p. 78). Along the same lines, one man reports: "There were nights when I didn't make it all the way. . . . But still I wanted her to feel that ... No 
offence meant. It was simply my little gift to her. No more, no less" ( $F O$, p. 200). When an orgasm is faked, the non-faking partner may feel special, having been able to give and perhaps share something as intimate as an orgasm. Thus, faking in the name of love also points to the perceived value of orgasm-as a sign of success.

\section{A Sign of Love-Take Two}

Inscribed in our thoughts and emotions concerning love and sex are cultural and social myths that shape our growth into adult women and men. According to Beauvoir, these myths tell us that it is desirable for a woman to passively exist to meet the needs of others (2010 [1949], pp.273, $294-5,311,334-5)$. At the same time, these myths tell us it is desirable for a man to be offered this kind of self-denial by a woman. She points to how women in our culture become used to perceiving themselves through the eyes of others, and to responding to and taking care of the needs of others, and how there is a risk that, even in the sexual domain, a woman will see herself as and make herself into an object for others (pp. 273, 294-5).

Faking an orgasm out of love might then, in terms of Beauvoir's account above, be a way for a woman to respond to and meet the man's need to experience himself as an accomplished lover. The contributions to $F O$, however, show that faking does not necessarily coincide with the female gender, as there are examples of men faking, as well as faking in same-sex relationships. Note, though, that Beauvoir's account in no way ascribes these differing roles to women and men as it were in essential terms. Her philosophical account, including many historical examples, points to the situation of women and the ways in which we become women as socio-cultural beings. Naturally, the gendered roles of women and men in Beauvoir's contemporary France of 1949, where women had had the vote for only five years, cannot be simply equated with the gender roles of contemporary Sweden which, together with the other Nordic countries, is ranked as having the greatest equality in the world according to the World Economic Forum's Global Gender Gap Report from 2011. But although some of the gendered binaries and myths inherent to Western thought may have changed slightly, others have proven to be more persistent.

If faking in the name of love is taken to be a sign of loving care, there are both women and men in Sweden who are prone to engage in such practices within an intimate relationship. This gives us reason to consider romantic love, what is called 'love' and how we "do love". Contemporary notions 
of love seem to harbour heteronormative ideas, in terms of a symbolically gendered binary, where loving care is coded as womanly/feminine. Political scientist Anna G. Jónasdóttir has focused on what is taken for granted as normal in the Nordic countries of today; love that is freely given and freely taken. She argues that love, and the existential forces at the heart of its power, is the driving force of society. She suggests that the typical relation between women and men as sexes today is one of political power, and that sexuality-as it is typically organized in contemporary Western societies- "affirms and fortifies essential social relations and distinctions between groups of people" (1991, p. 224-5). Problematizing the practice of love, she points to a specific kind of exploitation-the exploitation of loving capacities. She writes: "[i]f 'politics' has any particular core of significance it is about a field of power for wills and the consequences for will-power, where it is determined how we are with each other." She suggests that sex/gender relations constitute such a relatively independent field of power, in which there is "a complex and tangible struggle over who is master of the situation, who has the power to decide who is/does and /gets what, when and how." (p. 38). Social relations always consist of practices, societal practices-actions that reproduce these same relations. In this context, love is to be understood as a social, socio-sexual practice, where the two main elements of love are loving care and erotic ecstasy. She claims that the ways in which heterosexual love is institutionalized in contemporary society result in these two elements being positioned as opposites. Thus, according to Jónasdóttir, when (formally free and equal) women and men meet as sexes, the societal frames that condition these meetings are not equal. Women therefore tend to practice loving care, whereas men get to live/experience ecstasy, which becomes a means towards the end of selfassurance and personal growth.

The theoretical outline suggested by Jónasdóttir already in 1991 was later given empirical support in the socio-psychological research of Carin Holmberg (1993). Holmberg interviewed young, equal (as judged by others and themselves) couples without children, and analysed how their love and care were expressed in the actions and negotiations of everyday life. It turned out that while the women in these relationships tended to show more of loving care than the men did, they often simultaneously suppressed their own needs, calling that "love".

Questions of sexuality were not pursued at length in Holmberg's study, not for lack of interest but because she thought this would require 
an in-depth study of its own (p. 169). Still we can see how faking orgasms in the name of love has similarities with the loving care under scrutiny in Holmberg's investigation. In women's quest to fulfil men's wish to be special, the women who fake lovingly express loving care in a way that meets men's need to be capable of fulfilling the needs of women. But as has been stated earlier here, both women and men may fake in the name of love, which means that both sexes may practice loving care in this sense. Thus, the gendered, and heteronormative, binary of romantic love is not strictly realized in terms of genders, that is as women and men, but in the gendered practices of loving care in which both the "giving" of orgasm and the "delivery" of orgasm are important. Both signal the success of the sexual encounter, to the effect that both parties may experience the selfassurance of being successful lovers.

\section{A Sign of (Real) Sex Having Come to Completion}

In recent research on sex habits in Sweden and the U.S., faked orgasms emerge as a prevalent phenomenon. In his research, American sociologist Michael Kimmel describes what he calls the "orgasm gap". When young men and women were asked about whether they themselves and/or their partner had an orgasm the last time they were together, the women were fairly accurate in estimating their male partners' orgasms, whereas the men greatly overestimated the prevalence of their female partners' orgasms (2008, p. 210). Sandra Dahlén (2008, p. 156) discusses similar results from a Swedish population-based study of sexual habits from 1996: Sex in Sweden (Folkhälsoinstitutet, 2000). ${ }^{5}$ The mismatches in prevalence of experienced or perceived orgasms say nothing about the reasons for faking, however. Both sexes fake in order to put an end to the sex, in the name of love or for some other reason.

Let's start at the end. Orgasm and ejaculation are for many people the same as the end of sex. That is the overarching reason for faking; you want to get the sex over with when it's not working for you. With a credible faked orgasm, there is no need for inconvenient truth. (Ullholm 2008, p.201) 
Pelle Ullholm, engaged in education at RFSU (the Swedish Association for Sexuality Education) and specializing in masculinity and sexuality, points out that the male faker's best friend is the massive lack of knowledge about the non-existent connection between ejaculation and orgasm; if the ejaculation is seen as a guarantee of orgasm, the man who fakes does not even have to fake very well — if he can hide behind an ejaculation. Some of the male contributors to $F O$ also complain about this lack of knowledge, among former partners as well as among many of the sexual counsellors writing in weekly magazines, about this non-existent connection. The complaint is that these people seem to think that, for men, ejaculation is equivalent to orgasm. If so, there would be only two gradations: ejaculation or not equals orgasm or not-one or zero. But as one of the informants in FO states, "An ejaculation can be as enjoyable as blowing your nose, or like a vision of the cosmos, with all the gradations in between" (p. 203). The women in FO express similar thoughts, orgasms for women being a vast and varied experience as well, coming as it were, in all different shapes and sizes.

\section{The Cultural Signification of Orgasms-Heteronormative and Male}

The orgasm as a sign representing that "real sex" has occurred is symbolically and culturally coded as male. The model that serves for this phallic and normative ideal is what is perceived of as the male orgasm. One aspect of this is the inherent norm of the presumed connection mentioned above-that in which male orgasm equals ejaculation.

Another aspect is its being connected to a heterosexual norm, by which the notion of a "right" time and a "right" place for orgasm is conveyed. Tacit assumptions of erection as well as penetration are inherent to this ideal, and connected to its role within an ideal of heterosexual marriage. This means that a man's orgasm is supposed to occur within a woman's vagina, where it plays its "natural" role in the procreation of children (at times referred to as the "reproductive model") (Dahlén, 2008, p. 164).

As a consequence of this norm, other sexual practices are rendered less visible, and a notion of what male pleasure may be is restricted in ways that may have discriminatory undertones with regard to, for example, age and homosexuality (cf. Picket, 2011). A historical, albeit influential, example of the devaluation of ageing men's non-erectile practices is for 
example to be found in the Kinsey Reports, despite of its pronounced nonnormative ambitions:

In some of these males, ejaculation may occur without erection as a result of the utilization of special techniques in intercourse. In many older persons, erectile impotence is, fortunately, accompanied by a decline in and usually complete cessation of erotic response (Kinsey, Pomeroy and Martin, 1948, p.237).

Historian of ideas Åsa Andersson (2009) notes that the researchers' use of the term "fortunately" gives a hint as to why it is just as well that old men with erectile problems stop having sex-as if an ejaculation or orgasm without erection would somehow be tragic. She points to how, albeit not explicitly, a norm has been set for what heterosexual intercourse ought to be, where it seems that certain kinds of performance are more highly valued than sensations of pleasure.

The norm constructs some sexual practices as more correct, which makes other practices appear deviant, lacking or less successful (cf. Andersson, 2009; Picket, 2011; Saul, 2010). It is not surprising then that there are both women and men in $F O$ who write about having "faked away" their orgasms, in situations when they felt the orgasms came about at an inappropriate moment, that is, prior to a penetrating sex act (see, e.g., $F O$, pp. 111, 207). Several contributors in $F O$ tell of feelings of inadequacy with regard to their own bodies, such as feeling ashamed or being the object of shame for not being able to have orgasms in a relationship, or for not having them in accordance with some normative principle dictating when and how they should happen. The associated unhappiness has caused some of them to fake orgasms in order to appear normal and successful.

Further, for women this ideal—coded as it has been according to ideas about the masculine-is problematic in more ways than one. First, female orgasm is expected to coincide with features defined by the male norm, that is, the notion of what male pleasure and male orgasms "are" and are expected to be represents female pleasure and orgasms as being complementary or opposite to male pleasure and orgasms. Second, the norm is heterosexual and connected to the production of children. Thus the "right" time and place for a female orgasm is to be in accordance with 
what is expected of the male orgasm, through which the woman might get pregnant. In short: women are expected to have vaginal orgasms in conjunction with penetrating intercourse.

Complaints about male theorists either having taken their own experiences as exemplary and as the norm and model for descriptions of sexuality, or for attempting to control female sexuality, are common among feminist theorists and activists. In The Second Sex Beauvoir criticizes Freud among others for his mistaken view on female sexuality (cf. 2010 [1949], pp. 16-7, 418-9; Heinämaa, 2003, p. 73). Partly echoing Beauvoir's critique, Anne Koedt (1973) points to how Freud greatly influenced the norms for female sexuality when he "contended that the clitoral orgasm was adolescent, and that upon puberty, when women began having intercourse with men, women should transfer the center of the orgasm to the vagina" (p. 199).

Another aspect of how the symbolically male has informed the norms and ideas surrounding orgasm is mediated in language, where Jennifer Saul (2010) uses an example of the differentiation between 'sex' and 'foreplay'. 'Sex' is taken to refer to an activity in which someone (hopefully) achieves orgasm. Foreplay, on the other hand, is something else, not quite sex, but something that prepares us for the important and "real" activity. Foreplay is thus rendered a second-rate sexual activity, even though many women experience orgasm during activities referred to as foreplay. (Note that this should not be taken to mean that the division reflects the experiences of most women, or those of most men, nor that what is referred to as foreplay should necessarily be of special interest to women.) What is conveyed through this linguistic division is not innocent, as it helps shape our thoughts and experiences regarding such matters. It is important to bear in mind, however, that the script provided to men is as conditioned by historical and cultural context as that provided to women.

\section{Orgasm Depicted as Connected to Subordination and Violence}

Some cultural "scripts" portray male sexuality as being conditioned in terms of violence or subordination. Catherine MacKinnon and Andrea Dworkin have argued that pornography depicts the subordination of woman as a condition for male orgasm. That is, in their view female subordination is represented both as something that kindles desire and as what conditions orgasm. They argue that pornography thus fashions 
women's as well as men's desire to fit the roles of victim and perpetrator, respectively, and that these roles are then portrayed as being natural forms of sexual expression and of the sexes (Dworkin, 1981; 1989; MacKinnon, 1987; 1993).

It is easy to connect such cultural representations of natural roles within a heterosexual matrix: until recently, rape within marriage did not exist as a legal concept. Rape within marriage was not criminalized in Sweden until 1965. It was long seen neither as a societal problem nor as a concern for the public prosecutor. To put it crudely: the "right thing" had happened in the "right place".

The notion of the "right things" happening in the "right places" has in later years found a deeply homophobic and violent expression in the hate crime corrective rape. Lesbian women in South Africa have come forward to tell of systematic rapes, where the perpetrators ascribe a "corrective" function to rape (Mufweba 2003; Reddy et al. 2007). Rape, and rape as a weapon of war, has been dealt with by feminist philosophers such as Claudia Card and Susan Brison (Card 1996; Brison 1997). When rape is used as a weapon, male orgasm is connected to violence in ways that are closely connected to the victim/perpetrator roles Dworkin and MacKinnon argue are formed in part through pornography.

Although neither orgasms nor faking them have to be connected to violence or subordination, such cultural "scripts" do exist in the realm of sex and orgasm. Authors such as Aurdre Lorde (1984) and Martha Roth, who is one of the contributors to as well as one of the editors of Transforming a rape culture (1993), envision better scripts to come. But even in the absence of violence or subordination, there are always some kinds of scripts that "have to be" followed. Should we be surprised, then, that there are women, as well as men, who complain of not even experiencing desire?

\section{Expected to Desire}

Both sexes may feel they are expected to be interested in having sex at times when they actually are not. Failing to achieve orgasm may signal an overall lack of desire, as well as lack of pleasure.

Many men claim they find it hard to say no to sex even when they do not feel like it. It may clash with expectations. ... those of others as well as their own. It is not unusual 
for men to assume they are "on" all the time, despite the fact that desire varies and is connected to how you feel otherwise. (Ullholm 2008, p. 201)

When people contact RFSU about sexual problems (instead of, for example, concerns about pregnancy or sexually transmitted diseases), the most common question concerns lack of desire (more often posed by women), closely followed by questions about erectile problems (commonly posed by men). One might ask whether changed norms for male sexuality would make it easier for men to address the question of lack of desire, instead of having it framed as a matter of erectile dysfunction.

The expected and valued quest for orgasm may even forego the onset of desire or arousal. One example is given by a woman and feminist who writes about how she came to feel that she was not faking the orgasm, but faking herself. She had always felt having orgasms was important-and having them as often as possible (in the appropriate circumstances). She took this as a sign that she was living the good feminist life. At times when she had a hard time coming, even becoming aroused, she would instead go numb in certain respects and fantasize about things that eventually led to orgasm. At the same time she felt like she was somewhere else, and she did not like her fantasies as they were about being abused and forced. Eventually, because she "would do almost anything to have an orgasm", she began to feel she was faking "inside herself" and to herself; it seemed that the orgasm had become more important to her than whether she really wanted to have sex. With time, she writes, she has changed her ways with regard to having sex; she has quit having fantasies that make her feel outside the situation, elsewhere and powerless, instead allowing herself to say: "Let's stop, I've lost the urge", or something similar. For her this means that she feels better about herself and her sex life (FO, pp. $150 \mathrm{ff}$.).

\section{Faking as a Means to an End}

As was stated earlier in the essay, two of the reasons given for faking in $F O$ were faking in the name of love and faking to put an end to the sex. Although there seem to be some notable differences between these two types of faking, there are similarities as well. Both kinds are instrumental, they are performed in order to achieve something else, that is, the sounds and movements signalling pleasure are used as a means to an end - to end 
the sex in a way that signals that the "essential end", the orgasm, has been achieved. This is in contrast to when the expressions of pleasure are ends in themselves, as a source of enjoyment regardless of what follows. The instrumental faker may see the faking as a convenient way to put an end to the sex. But faking as a means may have more distant ends than this. One of the women in $F O$ even gives faked orgasms their due, as being what helped her climb the social ladder (p. 16-8).

The loving faker may believe s/he is performing an act of love. But one may well ask to what extent faking can be an act of love, regardless of how lovingly it is performed? Love and acts of love are typically understood as being ends in themselves. If what a partner erroneously perceives as acts of love turn out to have been instrumental, s/he will be prone to feel manipulated and trust will be difficult to restore. Trust and its counterpoint, distrust, are self-reinforcing (cf. Hertzberg, 1988; Lagerspetz, 1997; Kalman, 1999). Several stories in $F O$ support this kind of process, where the disclosure of earlier faked orgasms has had a detrimental effect on the relationship.

In an instrumental approach one's attention is focussed on the movements and expressions of the other person as things to be dealt with, or even manipulated, thereby simultaneously reducing the partner to a fact of/in one's world. Interestingly enough, as the focus is not on feeling and experiencing whatever happens, one's own body is also reduced to a thing, an instrument of one's will, as one's focus is bent on dealing with the other using one's own body.

\section{Habitual Faking}

For some who turn to faking, an instrumental attitude and behaviour may develop into a habit, a lived experience that resides in the body, a lived body with a lived experience of faking. As Merleau-Ponty points out, we acquire the ability to react to certain situations using certain kinds of solutions (1962 [1945], p. 142). The body is a situation, and it is the body that "understands' when a habit is acquired" (pp. 143-4). In the habit, there is agreement between what we aim to do and what we do, and our body is our anchor in the world. When encountering situations similar to those in which the habit was once acquired, our body is our means of handling the situation, that is, practice makes perfect. One way of dealing with certain situations has become a habit, such that the habit becomes 
the terms on which one experiences similar situations. Several stories in FO support these notions, in that contributors report experiencing difficulty not responding with faking at later occasions-especially with that same partner, but in some cases even with other partners. Thus, a practice that was intended to "resolve" certain situations may eventually end up as a lasting tendency (cf. Kalman 1999, pp. 102-9).

\section{Faking - as an End in Itself}

If the faked orgasm is part of play it may well be experienced as pleasurable by the faker. In that case, the faking can be regarded as an end in itself, and for the faker at least, as part and parcel of erotic play. One woman writes: "I have probably faked orgasm over a hundred times. I find that to be completely normal and a natural part of the play of flirt, seduction and sex" (FO, p.11). Erotic encounters are often marked by play-be it imitation, role-play, or something like hide-and-seek or "Simon Says". When aroused one may want to express and represent this arousal, thereby entering the role of the aroused.

Given the nature of role-play it is hardly surprising that a faked orgasm may be unintended as well, and surface as an effect of misunderstanding, where the partner perceived expressions of pleasure as signs of orgasm. In such cases, the faker may well choose to stick to the more or less unintended faked orgasm, so as not to break the pleasurable and playful mood of intimacy and lovemaking. "Oh, you've been longing for me, my boyfriend cooed, and naturally he enjoyed it when I (in complete honesty) more or less screamed with delight, and (completely falsely) seemed to have been quick to come. And I didn't have the heart to tell him" ( $F O$, p.241).

There is further a certain enjoyment in the development of a skill, even though such pleasure might not be described as playful. For some, the ability to act, perform, and master their own bodies in line with what is perceived as others' expectations and "needs" is one such skill. One's idea of self-becoming may then be focused on a desire to be someone who can be and stay in control, of others and oneself.

But there is also another sense in which control and power can be at play in the sexual encounter. For some, one aspect of withholding an orgasm and faking one instead is the sense of being in full control and not letting the other person get intimate. In Beauvoir's novel Les 
mandarins (1954) a woman-during intercourse with a man who is obsessed with synchronicity-is rather irritated, and thinks to herself that they would be no less separated even if they were to experience orgasm simultaneously. Yet somehow she feels defeated and sighs and moans, albeit not convincingly enough, because he asks her whether she came. Giving an affirmative answer, she thinks to herself that he has been defeated as well, as he did not pursue the question.

\section{Playful Loving - an End in Itself}

Until now, most of the paper has been devoted to exploring the instrumentality of faked orgasms. But what about the background of faked orgasms, what the faker is faking, namely the pleasure of sexual activities that are enjoyed as ends in themselves?

The mark of erotic encounters in which sexual acts are ends in themselves is closeness and the accompanying possibility of play. MerleauPonty describes the way our movement, touch and gestures are filled with meaning, just as our words are, and how it is through our bodies that we understand other people (1962 [1945], pp. 185-6). We convey messages through our lived bodies - through our way of walking, talking and even making love. Sexuality, knowledge and action exist in a relationship of reciprocal expression (p. 157). We can see, hear, and touch, as well as be seen, heard, and touched - by ourselves and by our partner (cf. pp. 92-3).

What becomes especially marked in an erotic encounter is that we do notonlyget to know theother person throughourbody, butwealsoget to know our own body through the other person's (cf. Kalman 1999, p. 150, n. 166). Sexual activities may have many ends, such as "inhabiting" or dwelling in a sexuality that is charged; enjoying touch, play and arousal may also be an end in itself. Here, some readers may remember the cuddling, kisses and petting of their youth, along with the pleasurable discovery of bodies - their own and others-as being an almost ecstatic state in which space and time could become blurred.

Merleau-Ponty describes how we can invite sleep by lying down or sitting comfortably, emptying the mind, and breathing slowly (pp. 163-4). Along similar lines several contributors to $F O$ write about having discovered ways to invite sensuous and ecstatic experience for themselves. As one woman in $F O$ states: "If there is something I have learned, ... it's that it's up to me, that it does require a bit of concentration 
and fiddling about" (p. 28). ${ }^{6}$ On one's own or together with someone else, one may discover how to invite and awaken pleasurable feelings. Sneezing and sleeping cannot be willed, nor can sexual pleasure-but they can be "invited". Several contributors point out that an orgasm is not something you get (from your lover), it is something you take. As one woman puts it: "You are not given an orgasm, you take it" ( $F O$, p. 138), and another writes: "For me it has always been natural to take responsibility for my own sexuality, to participate myself in achieving an orgasm. I would never blame a partner for the failure of pleasure to come off' (p. 15). The anonymous body both limits and enables experience, and may well elude our, as well as others', deliberate attempts at control.

To make love is also to play, and in play there is a kind of uncertainty. The uncertainty lies in the absence of rules, or rules that might suddenly be changed—neitherpartyknowswheretheplayfulattitudewill takethem. María Lugones describes how the attitude of playfulness turns an activity into play:

...the attitude that carries us through the activity, a playful attitude, turns the activity into play. Our activity has no rules, though it is certainly intentional activity and we both understand what we are doing. The playfulness that gives meaning to our activity includes uncertainty, but in this case the uncertainty is an openness to surprise. This is a particular metaphysical attitude that does not expect the world to be neatly packaged, ruly. Rules may fail to explain what we are doing. We are not self-important, we are not fixed in particular constructions of ourselves, which is part of saying that we are open to self-construction. We may not have rules, and when we do have rules, there are no rules that are to us sacred. We are not worried by competence. We are not wedded to a particular way of doing things.... We are there creatively. (Lugones, 1996, p.431, italics in original)

A playful attitude renders us accessible to the surprise of the body's capacity for joy and pleasure, and the associated openness to outcome will then not implicitly hinge on an orgasm. There does not need to be a script with a self-evident end. A playful attitude in which we are open to selfcreation is also one in which we recreate each other in reciprocity. In her description of a lesbian act of love, Simone de Beauvoir relates how 
the body of a lover may be seen as a possibility to recreate oneself in reciprocity (2010 [1949], p. 429). I take this to be a description of human possibility as well. In the words of a 29 -year old male from Stockholm:
I think faked orgasms are a shame, but I have faked myself. I think it's more common for women to fake than for men to do it. If men would stop being so damned hurt by sex not being like it is in pornographic movies, women wouldn't have to fake to keep the man in a good mood. I'd rather have a moment of genuine sex without orgasm, than a moment of sex with make-believe orgasm (FO, p. 206).

\section{References}

Alakoski, Susanna \& Amanda Mogensen, (Eds.) (2008). Fejkad orgasm (Faked Orgasm Stockholm: Ordfront förlag, 2008.

Andersson, Åsa. (2009). "Från fula gubbar och liderliga gummor till vitala casanovor och glada änkor: om 1900-talets förändrade synsätt på äldres sexualitet". (From dirty old men and lascivious old women to vigourous Casanovas and merry widows: on the changed perspectives on the sexuality of elderly during the 20th century). Tidskrift for genusvetenskap. (2009:4, pp. 47-71).

Beauvoir, Simone de (2010 [1949]). The second sex (La deuxième sexe). 1st American ed. New York: Alfred A. Knopf

Beauvoir, Simone de. (1954). Les mandarins (novel). Paris: Gallimard.

Brison, Susan. J. (1997). "Outliving oneself: Trauma, memory and personal identity". In: Diana Tietjens Meyers (Ed.) Feminists rethink the self. Boulder, Colo.: Westview Press. (pp.12-39)

Card, Claudia. (1996). "Rape as a weapon of war". Hypatia, (11 (1996): 4, pp. 5-18).

Dahlén, Sandra. (2008). "Varför fejkar så många kvinnor orgasm?” (Why do so many women fake orgasms?). In: Susanna Alakoski \& Amanda Mogensen (Eds.), Fejkad orgasm (Faked Orgasm). Stockholm: Ordfront förlag. (pp. 155-168)

Dworkin, Andrea. (1981). Pornography: men possessing women. London: Women's Press.

Dworkin, Andrea. (1989). Letters from a war zone: writings 1976-1989. New York: Dutton.

Elmerstig, Eva, Wijma, Barbro, \& Berterö, Carina. (2008). "Why do young women continue to have sexual intercourse despite pain?". The Journal of Adolescent Health: Official Publication of The Society For Adolescent Medicine, 43(4), pp. 357-363.

Elmerstig, Eva. (2009). Painful ideals: young Swedish women's ideal sexual situations and experiences of pain during vaginal intercourse. Dissertation. Linköping : Linköpings universitet, 2009. Linköping.

Folkhälsoinstitutet (2000). Sex in Sweden: on the Swedish sexual life 1996. (1. ed.) Stockholm: National Institute of Public Health (Folkhälsoinstitutet). 


\section{Janus Head}

Haug, Frigga. (1999). Female sexualization: a collective work of memory. London: Verso. Heinämaa, Sara. (2003). Toward a phenomenology of sexual difference: Husserl, MerleauPonty, Beauvoir. Lanham, Md.: Rowman \& Littlefield Publishers.

Hertzberg, Lars. (1988). "On the Attitude of Trust". Inquiry (31 (1988): pp.307-22).

Holmberg, Carin. (1993). Det kallas kärlek: en socialpsykologisk studie om kvinnors underordning och mäns överordning bland unga jämställda par (It's Called Love: A social psychological study of the woman's subordination and the man's superordination among young, equal couples). Göteborg: Anamma förlag.

Jónasdóttir, Anna G. (1991). Love power and political interests: towards a theory of patriarchy in contemporary western societies. Diss. Göteborg : Univ. Örebro.

Kalman, Hildur. (1999). The structure of knowing: Existential trust as an epistemological category. Dissertation. Umeå : Univ.. Umeå.

Kalman, Hildur. (2008). "Njutning eller fejk? - en filosofisk betraktelse" (Pleasure or fake? A philosophical reflection). In: Susanna Alakoski \& Amanda Mogensen (Eds.), Fejkad orgasm (Faked Orgasm). Stockholm: Ordfront förlag. (pp. 39-62).

Kinsey, Alfred C., Pomeroy, Wardell B. \& Martin, Clyde E. (1948). Sexual behavior in the human male. Philadelphia: Saunders.

Kimmel, Michael S. (2008). Guyland: the perilous world where boys become men. (1st ed.) New York: Harper.

Koedt, Anne. (1973) The Myth of the Vaginal Orgasm”. In: Anne Koedt, Ellen Levine, and Anita Rapone (Eds.), Radical Feminism. New York: Quadrangle. (pp. 198-207)

Lagerspetz, Olli. (1997). Trust: The Tacit Demand. Vol 1 Library of Ethics and Applied Philosophy: Kluwer Academic Pub.

Lorde, Aurdre. (1984). "Uses of the Erotic: The Erotic as Power". In: Sister outsider: essays and speeches. Trumansburg, N.Y.: Crossing Press.

Lugones, María. (1996). "Playfulness, 'world'-traveling, and loving perception”. In: Ann Garry, and Marilyn Pearsall (Eds.), Women, knowledge, and reality, ${ }^{\text {nd }}$ ed. New York: Routledge. (pp. 419-433)

MacKinnon, Catharine. (1987), Feminism Unmodified: Discourses on Life and Law, Cambridge, MA: Harvard University Press.

MacKinnon, Catharine. (1993). Only Words, Cambridge, MA: Harvard University Press.

Merleau-Ponty, Maurice. (1962 [1945]). Phenomenology of perception. London: Routledge.

Mufweba, Yolanda. (2003). "Corrective rape makes you an African woman". IOL: News for South Africa and the World. (published on the Web by IOL 2003-11-07) http:// www.int.iol.co.za/index.php?click_id=ct20031107212728265P430805\&set_id=1 (retrieved February $11^{\text {th }} 2008$ )

Pickett, Brent. (2011). "Homosexuality". In The Stanford Encyclopedia of Philosophy (Spring 2011 Edition), Edward N. Zalta (ed.), URL = <http://plato.stanford.edu/ archives/spr2011/entries/homosexuality/>.

Reddy, Vasu, Potgieter, Cheryl-Ann \& Mkhize, Nonhlanhla. (2007). "Cloud over rainbow nation”. In HSRC Review vol. 5, no. 1 March 2007. http://www.hsrc.ac.za/ HSRC_Review_Article-51.phtml (retrieved February $11^{\text {th }}$ 2008)

Roth, Martha. (1993). "Transforming the rape culture that lives in my skull”. In: Emilie Buchwald, Pamela R. Fletcher, and Martha Roth (Eds.), Transforming a rape culture (pp. 405-15). Minneapolis, Minn.: Milkweed editions.

Sandberg, Mattias. “'Ta över Victoria': När alla skandaler briserade räddade hon familjens rykte" ("'Take over Victoria': When all the scandals exploded she saved the family 
reputation"). Aftonbladet (Stockholm), 26 Dec. 2010.

Saul, Jennifer. (2010). "Feminist Philosophy of Language". In: The Stanford Encyclopedia of Philosophy (Fall 2010 Edition), Edward N. Zalta (ed.), URL = <http://plato. stanford.edu/archives/fall2010/entries/feminism-language/>.

Sundén Jelmini, Maria. "Överlämningen en kompromiss" (The delivery a compromise). Svenska Dagbladet (Stockholm), 20 June 2010.

Ullholm, Pelle. (2008). ”Visst fejkar män!” (Indeed—men are faking!). In: Susanna Alakoski \& Amanda Mogensen (Eds.), Fejkad orgasm (Faked Orgasm). Stockholm: Ordfront förlag. (pp. 201-2)

Young, Iris Marion. (2005). On Female Body Experience: "Throwing like a girl and other essays". Oxford: Oxford University Press.

Electronic sources:

NORDICOM, Nordic Information Centre for Media and Communication Research: http:// www.nordicom.gu.se/eng.php - retrieved 2012-04-17

World Economic Forum. The Global Gender Gap Report 2011: http://www.weforum. org/ - retrieved 2012-04-27

Notes

${ }^{1}$ None of the contributors, academic or otherwise, or the editors are receiving any payment or royalty for their contributions to the book. In the invitation to write, it was stated that every contribution was considered a gift to the project and to humanity. All income generated by the book is given to an organization, NSKK, working at the grassroots level outside of Kolkata in India with sexual education for young people, and supplying sanitary towels to young women.

${ }^{2} \mathrm{~A}$ much earlier, Swedish, version of this paper has been published in the book Fejkad Orgasm (Kalman 2008). Parts of the current version have been presented at conferences in Utrecht in 2009, Oslo in 2010 and Umeå in 2011, and at seminars at the universities of Melbourne, Linköping and Umeå, respectively. I thank the audiences at these conferences, seminars and symposia, and the anonymous reviewers for Janus Head for their insights and helpful suggestions.

${ }^{3}$ This and all the following translations of citations from the anthology Fejkad Orgasm are mine.

${ }^{4}$ These examples from American popular culture are not foreign to the Swedish publicon the contrary. These series and the film have been shown and rerun on several Swedish TV channels for many years. The impact of American popular culture can hardly be overestimated, as for example more than $40 \%$ of what was shown on the five biggest TV channels in 2010 was produced in the US, which is comparable to the amount produced in Sweden. If productions of British origin are added to the American productions, these make up 50\% of what is offered to the Swedish televiewer. Cinema film premieres in Sweden show comparable numbers: circa 50\% are of North American origin. If one focuses on what viewers between 15-24 watch most of the time, that is drama, series and films (57\% of their TV watching time in 2010), the North American cultural dominance is even greater (all statistics from NORDICOM, Nordic Information Centre for Media and 


\section{Janus Head}

Communication Research: www.nordicom.gu.se/eng.php - retrieved 2012-04-17).

The question of impact on the audience is another issue of course, but two examples may give a hint. When teaching ethics in the Basic Training Programme for Police Officers at Umeå University, my colleague teachers who were police officers told me that nowadays, when Swedish police officers are about to make a search of a premises, they are commonly asked to present "the search warrant". This is noteworthy as according to Swedish law there is no need for a search warrant. The expectation is obviously based on what people have seen on TV-that is, American legal practice. And most Swedish lay persons know more about American procedures in the court room, from having watched a series of dramas etc. on the subject-whereas few have seen the inside and know the practices of a Swedish court room. The next example is from the topic of weddings: it has become common when planning for a wedding that young women in Sweden ask for a ceremony in which their fathers walk them down the aisle in order to "give them away". This has evoked some debate, and many pastors refuse to abide by this wish or at least question it. The reason is that this "giving away" of the bride is perceived of as a patriarchal tradition, foreign and opposed to the Swedish custom, which is for the two parties to walk down the aisle side by side as two equals. This gradual change in customs, where young women perceive of the "giving away" as a romantic part of a wedding, is often interpreted as an effect of the obvious fact that most people have witnessed more American weddings on TV and in films than Swedish weddings in real life or on TV. Thus, when the Swedish crown princess and the king, in their preparations for her wedding the $19^{\text {th }}$ of June 2010, expressed the wish that the king walk her down the aisle, there was a heated public debate. This led to a historical compromise whereby the king walked the princess halfway down the aisle, where the bridegroom was waiting, and then the couple continued their walk according to the Swedish custom (Sundén Jelmini 2010; Sandberg 2010).

${ }^{5}$ The report is based on responses from a total of 2810 respondents. The net sample consisted of 4781 individuals between the ages 18-74, and of these 2810 (59\%) took part in the study.

${ }^{6}$ This citation is not intended to imply that women's bodies are more complicated than men's bodies when it comes to the ability to experience pleasure. Rather, it means that in a culture where girls' bodies and body parts are the objects of shame earlier, more deeply and to a larger extent than are the bodies of boys (Haug, 1999) and where norms for sex are heteronormative and connected to the notion of penetration, for some this "fiddling" may have to be given some scope. 